\title{
RESEARCH
}

Open Access

\section{Endometrial regeneration with endometrial epithelium: homologous orchestration with endometrial stroma as a feeder}

Ryo Yokomizo 1,2,3, Yukiko Fujiki ${ }^{1}$, Harue Kishigamii ${ }^{1}$, Hiroshi Kishi ${ }^{3}$, Tohru Kiyono ${ }^{4}$, Sanae Nakayama', Haruhiko Sago ${ }^{2}$, Aikou Okamoto ${ }^{3}$ and Akihiro Umezawa ${ }^{1 *}$

\begin{abstract}
Background: Thin endometrium adversely affects reproductive success rates with fertility treatment. Autologous transplantation of exogenously prepared endometrium can be a promising therapeutic option for thin endometrium; however, endometrial epithelial cells have limited expansion potential, which needs to be overcome in order to make regenerative medicine a therapeutic strategy for refractory thin endometrium. Here, we aimed to perform long-term culture of endometrial epithelial cells in vitro.

Methods: We prepared primary human endometrial epithelial cells and endometrial stromal cells and investigated whether endometrial stromal cells and human embryonic stem cell-derived feeder cells could support proliferation of endometrial epithelial cells. We also investigated whether three-dimensional culture can be achieved using thawed endometrial epithelial cells and endometrial stromal cells.

Results: Co-cultivation with the feeder cells dramatically increased the proliferation rate of the endometrial epithelial cells. We serially passaged the endometrial epithelial cells on mouse embryonic fibroblasts up to passage 6 for 4 months. Among the human-derived feeder cells, endometrial stromal cells exhibited the best feeder activity for proliferation of the endometrial epithelial cells. We continued to propagate the endometrial epithelial cells on endometrial stromal cells up to passage 5 for 81 days. Furthermore, endometrial epithelium and stroma, after the freeze-thaw procedure and sequential culture, were able to establish an endometrial three-dimensional model.

Conclusions: We herein established a model of in vitro cultured endometrium as a potential therapeutic option for refractory thin endometrium. The three-dimensional culture model with endometrial epithelial and stromal cell orchestration via cytokines, membrane-bound molecules, extracellular matrices, and gap junction will provide a new framework for exploring the mechanisms underlying the phenomenon of implantation. Additionally, modified embryo culture, so-called "in vitro implantation", will be possible therapeutic approaches in fertility treatment.
\end{abstract}

Keywords: Endometrial regeneration, Endometrial epithelium, Endometrial stroma, Human embryonic stem cell, Three-dimensional culture

\footnotetext{
* Correspondence: umezawa@1985.jukuin.keio.ac.jp

'Center for Regenerative Medicine, National Center for Child Health and Development Research Institute, 2-10-1 Okura, Setagaya, Tokyo 157-8535, Japan

Full list of author information is available at the end of the article
}

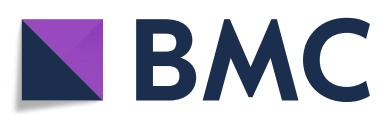

(- The Author(s). 2021 Open Access This article is licensed under a Creative Commons Attribution 4.0 International License, which permits use, sharing, adaptation, distribution and reproduction in any medium or format, as long as you give appropriate credit to the original author(s) and the source, provide a link to the Creative Commons licence, and indicate if changes were made. The images or other third party material in this article are included in the article's Creative Commons licence, unless indicated otherwise in a credit line to the material. If material is not included in the article's Creative Commons licence and your intended use is not permitted by statutory regulation or exceeds the permitted use, you will need to obtain permission directly from the copyright holder. To view a copy of this licence, visit http://creativecommons.org/licenses/by/4.0/. The Creative Commons Public Domain Dedication waiver (http://creativecommons.org/publicdomain/zero/1.0/) applies to the data made available in this article, unless otherwise stated in a credit line to the data. 


\section{Background}

Infertility is defined as a failure to conceive after 12 months of regular and unprotected sexual intercourse and is estimated to affect $8-12 \%$ of couples of reproductive age [1]. Various etiologies are associated with infertility, and endometrium is recognized as one of the significant factors [2]. Endometrium is structurally divided into two indistinct layers, epithelial cells and stromal cells, and undergoes remarkable histological and structural changes throughout the menstrual cycle in preparation for embryonic implantation and subsequent shedding and regeneration in non-conception cycles. Endometrial thickness and a sonographic pattern of the endometrium are widely accepted as prognostic indicators for endometrial receptivity; lower endometrial thickness is associated with lower pregnancy rate and live birth rate [3]. Regardless of its significance, gynecologists often perform dilatation and curettage for spontaneous miscarriage and abortion [4], and interventional radiologists perform embolization for feeding arteries to control vaginal bleeding or reducing size of uterine myoma in clinical practice [5]; nevertheless, these invasive interventions cause endometrial damage and result in thin endometrium $[6,7]$.

Thin endometrium adversely affects reproductive success rates with fertility treatment [8]. Several treatment modalities are presented to patients with thin endometrium to improve endometrial thickness [9]. These approaches comprise estradiol replacement, supplementation of elemental minerals and vitamins, and uncountable experimental approaches. Regenerative medicine including application of platelet-rich plasma (PRP) and cell therapy utilizing menstruation-derived stem cells is expected to be a promising therapeutic strategy $[10,11]$. However, these strategies are not broadly available and there is no reliable clinical evidence supporting their use. Autologous transplantation of exogenously prepared endometrium is currently a challenge for clinical practice [12]. In addition, endometrial organoid with endometrial cells is established [13], but endometrial epithelial cells themselves have not been cultured in vitro. Considering these limitations, further study is needed to determine how to maintain endometrial epithelial cells efficiently under xeno-free conditions.

We herein established a model of in vitro-cultured endometrium as a potential therapeutic option for refractory thin endometrium. The three-dimensional culture model with endometrial epithelial and stromal cell orchestration will provide a new framework for exploring the mechanisms underlying the phenomenon of implantation. Additionally, modified embryo culture, so-called "in vitro implantation", will be possible therapeutic approaches in fertility treatment.

\section{Methods}

\section{Human tissue collection}

Endometrial specimens without any abnormalities or malignancies were obtained from women of reproductive age undergoing hysterectomy for benign gynecological diseases after written informed consent. Characteristics of donor individuals are provided in Table 1.

Endometrial epithelial cells and stromal cells were isolated from endometrial tissues as reported previously [14]. Briefly, after enzymatic digestion of minced tissue with $100 \mu \mathrm{g} / \mathrm{ml}$ collagenase type 1 in a shaking incubator for $2 \mathrm{~h}$ at $37^{\circ} \mathrm{C}$, cells were separated by filtration through $100 \mu \mathrm{m}$ and $40 \mu \mathrm{m}$ nylon mesh. The dispersed fragments were collected by centrifugation, resuspended in DMEM-high glucose (Gibco, catalog number 11965118) containing $1 \%$ penicillin-streptomycin (Gibco, cata$\log$ number 15140-122) and $10 \%$ fetal bovine serum (Gibco, catalog number 16000-044) and seeded on biocoat culture dishes (Corning, catalog number 354450) as endometrial stromal cells. The residual tissue fragments and cell clumps were collected into a new $50-\mathrm{ml}$ tube using Accumax (Innovative Cell Technologies, catalog number AM105) and 0.25\% Trypsin/EDTA (Gibco, cata$\log$ number 25200-056) and then incubated for $10 \mathrm{~min}$ at room temperature with continuous pipetting. Cells separated by filtration through a $40-\mu \mathrm{m}$ nylon mesh, which were regarded as endometrial epithelial cells, were

\section{Table 1 Patients' information}

\begin{tabular}{ll}
\hline Parameters & Mean \pm SD \\
Age & $47.0 \pm 2.8$ \\
BMI & $23.4 \pm 4.1$ \\
BMI, body mass index; SD, standard deviation & N \\
Parameters & \\
Gynecological disorder (including duplication) & 9 \\
Uterine myoma & 3 \\
Endometriosis & 2 \\
Ovarian tumor & 1 \\
Adenomyosis & \\
Operation & 5 \\
Abdominal hysterectomy & 4 \\
Laparoscopic hysterectomy & \\
Menstrual regularity & 3 \\
Regular & 4 \\
Irregular & 2 \\
Unknown & 2 \\
Menstrual phase & \\
Proliferative & \\
Secretory & \\
Unknown & \\
\hline
\end{tabular}


resuspended in ESTEM-HE medium (GlycoTechnica, Japan) and seeded on culture dishes. Portions of endometrial epithelial cells were frozen with Stem Cellbanker (Nippon Zenyaku Kogyo, Japan) in $-80^{\circ} \mathrm{C}$. Endometrial stromal cells and epithelial cells were incubated at $37^{\circ} \mathrm{C}$, 95\% air and $5 \% \mathrm{CO}_{2}$. These cells were passaged serially when they reached confluent by using TrypLE Express (Gibco, catalog number 12605-010) and frozen with STEM CELLBANKER in $-80^{\circ} \mathrm{C}$.

\section{Immunocytochemical analysis}

Cells were fixed with $4 \%$ paraformaldehyde (PFA) in PBS for $10 \mathrm{~min}$ at $4{ }^{\circ} \mathrm{C}$. After washing with PBS and treatment with $0.1 \%$ Triton X-100 (Sigma-Aldrich, \#T8787-100 ML) for $10 \mathrm{~min}$ at $4{ }^{\circ} \mathrm{C}$, the cells were incubated with Protein Block Serum-Free Ready-To-Use (Dako, \#X 0909) for $30 \mathrm{~min}$ at room temperature, followed by reaction with primary antibody in blocking buffer for $24 \mathrm{~h}$ at $4{ }^{\circ} \mathrm{C}$. After washing with PBS, the cells were incubated with fluorescently conjugated secondary antibody. Anti-rabbit or anti-mouse immunoglobulin G (IgG) bound to Alexa 488 or 546 (1:1000) was incubated in blocking buffer for $30 \mathrm{~min}$ at room temperature. The nuclei were stained with DAPI (Biotium, \#40043). All images were captured using confocal microscopy (confocal microscope $\mathrm{C} 2+$ ) or fluorescence microscopy (BZ$\mathrm{X} 700$, KEYENCE). Antibody information is provided in Table 2.

\section{Decidualization}

For decidualization, endometrial stromal cells were plated in 6-well plates, then the cells were cultured for 8 days in DMEM supplemented with low-serum medium (2\% FBS), $10 \mathrm{nM} \beta$-estradiol (E2758, Sigma-Aldrich, Saint Louis, MO, USA), $1 \mu \mathrm{M}$ progesterone (E8783, Sigma-
Aldrich, Saint Louis, MO, USA), and $0.5 \mathrm{mM}$ 8-Br-cAMP (B5386, Sigma-Aldrich, Saint Louis, MO, USA). Detail protocol is shown in Supplemental Figure 1.

\section{Real-time quantitative polymerase chain reaction}

RNA was extracted from cells using the RNeasy Mini kit (Qiagen, \#74104). An aliquot of total RNA was reversetranscribed using an oligo (dT) primer (Invitrogen, \#18418-020). For the thermal cycle reactions, the cDNA template was amplified (Applied Biosystems Quantstudio 12 K Flex Real-Time PCR System) with gene-specific primer sets (Table 3) using the Platinum SYBR Green qPCR SuperMix-UDG with ROX (Invitrogen, \#11733046) under the following reaction conditions: 40 cycles of PCR $\left(95^{\circ} \mathrm{C}\right.$ for $15 \mathrm{~s}$ and $60^{\circ} \mathrm{C}$ for $\left.1 \mathrm{~min}\right)$ after an initial denaturation $\left(95^{\circ} \mathrm{C}\right.$ for $\left.2 \mathrm{~min}\right)$. Fluorescence was monitored during every PCR cycle at the annealing step. mRNA levels were normalized using glyceraldehyde-3phosphate dehydrogenase as a housekeeping gene.

\section{Preparation of mouse embryonic fibroblasts}

Mouse embryonic fibroblasts (MEF) were prepared for use as nutritional support cells (feeder cells). E12.5 ICR mouse fetuses (Japan CLEA) were excised and the fetus head, limbs, tail, and internal organs were all removed, minced with a blade, and seeded in culture dishes in a medium (DMEM containing 10\% FBS, 1\% Penstrep.) to allow cell growth. X-ray irradiation was applied (Hitachi, MBR-1520 R-3) to the cells in $1 / 100$ amount of $1 \mathrm{M}$ HEPES Buffer Solution (Invitrogen, 15630-106). Following irradiation with X-rays (dose, $30 \mathrm{~Gy}$ ), the cells were frozen using a TC protector (DS Pharma Biomedical, TCP-001) and subsequently used as feeder cells for culturing endometrial epithelial cells.

Table 2 List of antibodies for immunochemistry

\begin{tabular}{|c|c|c|c|}
\hline Name & Class & Company & Dilution \\
\hline \multicolumn{4}{|l|}{ Primary antibodies } \\
\hline Vimentin (D21H3) XP \#5741 & Rabbit lgG & CST & $1 / 100$ \\
\hline Anti-pan Cytokeratin antibody [AE1/AE3 + 5D3] ab86734 & Mouse $\operatorname{lgG} 1$ & abcam & $1 / 100$ \\
\hline Anti-Estrogen Receptor alpha antibody [ESR1/3557] ab259427 & Mouse $\operatorname{lgG} 1$ & abcam & $1 / 200$ \\
\hline Anti-Progesterone Receptor antibody [SP2] ab16661 & Rabbit lgG & abcam & $1 / 100$ \\
\hline Anti-CD10 antibody [EPR22865-73] ab255609 & Rabbit lgG & abcam & $1 / 50$ \\
\hline Anti-CD13 antibody [EPR4058] ab108310 & Rabbit lgG & abcam & $1 / 100$ \\
\hline Anti-E Cadherin antibody [HECD-1] ab1416 & Mouse $\operatorname{lgG} 1$ & abcam & $1 / 50$ \\
\hline \multicolumn{4}{|l|}{ Secondary antibodies } \\
\hline DAPI \#40043 & None & Biotium & $1 / 1000$ \\
\hline Goat anti-rabbit IgG Secondary antibody, Alexa Fluor 488 A1 1008 & None & Invitrogen & $1 / 500$ \\
\hline Goat anti-mouse lgG1 Secondary antibody, Alexa Fluor 546 A21123 & None & Invitrogen & $1 / 500$ \\
\hline
\end{tabular}


Table 3 List of primers for quantitative reverse transcriptionpolymerase chain reaction

\begin{tabular}{lll}
\hline Gene & \multicolumn{2}{l}{ Primer sequence } \\
\hline PRL & Forward & 5' TCATCTGGTCACGGAAGTACGT 3' \\
& Reverse & 5' GCCCTCTAGAAGCCGTTTGG 3' \\
IGFBP1 & Forward & 5' ATGGCTCGAAGGCTCTCCAT 3' \\
& Reverse & 5' TCCTGTGCCTTGGCTAAACTC 3' \\
GAPDH & Forward & 5' TGTTGCCATCAATGACCCCTT 3' \\
& Reverse & 5' CTCCACGACGTACTCAGCG 3' \\
\hline
\end{tabular}

PRL prolactin, IGFBP1 insulin-like growth factor binding protein 1, GAPDH glyceraldehyde 3-phosphate dehydrogenase

Preparation of human embryonic stem cell-derived feeder cells

The human embryonic stem cell line (SEES5) was maintained on irradiated MEF feeder layers [15]. To prepare human embryonic stem cell (hESC)-derived feeder cells, we processed SEES5 cells as previously reported [16]. Briefly, to generate embryonic bodies (EBs), SEES5 (5 $\times$ $10^{3} /$ well) were dissociated into single cells with $0.5 \mathrm{mM}$ EDTA (Life Technologies) after exposure to the rock inhibitor (Y-27632: A11105-01, Wako, Japan) and cultivated in 96-well plates (Thermo Fisher Scientific) in the EB medium (76\% Knockout DMEM, 20\% $35 \mathrm{kGy}$ irradiated Xeno-free Knockout Serum Replacement (XFKSR, Life Technologies, CA, USA), 2 mM GlutaMAX-I, $0.1 \mathrm{mM}$ NEAA, Pen-Strep, and $50 \mu \mathrm{g} / \mathrm{ml} \mathrm{l-ascorbic} \mathrm{acid}$ 2-phosphate (Sigma-Aldrich, St. Louis, MO, USA)) for 4 days. The EBs were transferred to T25 flasks coated with NMP collagen PS (Nippon Meat Packers Inc.) and cultivated in the XF32 medium (85\% Knockout DMEM, 15\% 35 kGy-irradiated XF-KSR, 2 mM GlutaMAX-I, 0.1 mM NEAA, Pen-Strep, $50 \mu \mathrm{g} / \mathrm{ml}$ l-ascorbic acid 2-phosphate, $10 \mathrm{ng} / \mathrm{ml}$ heregulin-1 $\beta$ (recombinant human NRG-beta 1/HRG-beta 1 EGF domain; Wako, Japan), $200 \mathrm{ng} / \mathrm{ml}$ recombinant human IGF-1 (LONGR3-IGF-1; SigmaAldrich), and $20 \mathrm{ng} / \mathrm{ml}$ human bFGF (Kaken Pharmaceutical Co. Ltd.)) for 60 to 70 days. We propagated them in $\alpha$-MEM medium supplemented with 10\% FBS (Gibco or HyClone) and 1\% Pen-Strep.

These cells were immortalized by inoculation with CSII-CMV-TERT, CSII-CMV-Tet-Off, CSII-TRE-Tightcyclin D1, and CSII-TRE-Tight-CDK4R24C (mutant CDK4: an INK4a-resistant form of CDK4) lentiviruses according to our previous report [17]. We further infected the immortalized cells with the lentiviruses carrying a combination of the R-WNT3A, R-SPO, and NOGGIN genes. We designated the hESC-derived feeder cells (hESCFCs) and named as listed in Supplemental Table 1. We propagated these cells in a gelatin (Sigma, G1890)-coated culture dish in $\alpha$-MEM medium supplemented with 10\% FBS (Gibco) and 1\% Pen-Strep to allow cell growth. For hESCFC-3 cultivation, we further added tetracycline into the medium. Using an X-ray irradiation apparatus (Hitachi, MBR-1520 R-3), 1/100 amount of $1 \mathrm{M}$ HEPES Buffer Solution (Invitrogen, 15630-106) was added to the feeder cells except for hESCFC-3. Following irradiation with X-rays (dose, 30 Gy), the feeder cells were frozen using a TC protector (DS Pharma Biomedical, TCP-001). We did not use Xray irradiation for hESCFC-3, and these cells were also frozen using a TC protector.

\section{Culture of endometrial epithelial cells}

Endometrial epithelial cells were cultured on feeder cells. We cultured the endometrial epithelial cells for approximately 2 weeks and then passaged them when they reached confluency or ceased colony enlargement. We continued to observe growth of small colonies and terminated the culture when the cells did not show the signs of proliferation. In serial passages, the feeder cells were detached from culture dishes 1-2 min after exposure to TrypLE Express, but colonies of endometrial epithelial cells remained attached on the dish. MEFs and hESCFCs were cultured on gelatin-coated dishes in $\alpha$-MEM supplemented with 10\% FBS (Gibco) and 1\% Pen-Strep as feeder cells. Endometrial stromal cells were cultured in DMEM (Gibco) supplemented with 10\% FBS (Gibco) and 1\% PenStrep. The endometrial epithelial cells were overlaid on the feeder cells in ESTEM-HE medium (GlycoTechnica, Japan). The media were replaced in 2 or 3 days.

\section{Assessment of cell proliferation}

Endometrial epithelial cells were plated into 24 well plates $\left(10 \times 10^{4} /\right.$ well $)$. In each well, corresponding feeder cells were plated in advance $\left(5 \times 10^{4} /\right.$ well $)$. Cell clusters appeared 2 to 3 days after seeding, and the medium was replaced every 2 or 3 days. Phase-contrast photomicrographs were taken at each passage when the cells reached subconfluence or stopped growing. Numbers of cells and colonies were counted in central field of pictures to compare feeder activities. Two investigators (R. Y. and Y.F) counted the total number of endometrial epithelial cells/well and the number of colonies formed, and calculated the area of colonies using imaging software Fiji [18]. These measurements were conducted entirely independent of all other variables. Each experiment was done in triplicate.

\section{Growth curves}

Endometrial stromal cells were plated into 6-well plates $\left(1 \times 10^{5} /\right.$ well $)$. The total number of cells/well, which was cultured in DMEM and ESTEM-HE medium, was counted $1,3,5,7$, and 10 days after the plating.

\section{Three-dimensional cell culture}

Three-dimensional cell culture was performed according to a previously described protocol [19]. Atelocollagen 
(Koken, \#IPC-50) and endometrial stromal cells were mixed and poured into an untreated $60-\mathrm{mm}$ Petri dish and allowed to gel at $37^{\circ} \mathrm{C}$ for $1 \mathrm{~h}$ to prepare the stromal layer. Contraction of the collagen gel was facilitated by pulling the gel from the surface of the Petri dish. The medium (DMEM) was changed every 2 or 3 days until day 7. Frozen-thaw endometrial epithelial cells were plated at $1 \times 10^{6}$ cells inside a glass ring $(10 \mathrm{~mm}$ diameter $)$ on the surface of the contracted collagen gel at Day 7 . Endometrial epithelial cells were grown in ESTEM-HE medium and the medium was replaced every 2 or 3 days. Three-dimensional endometrium was obtained on day 21.

\section{Statistical analysis}

Changes in gene expression were compared by paired $t$ tests. Unpaired Student's $t$ test was used to compare differences of continuous variables in two groups and one-way ANOVA was used in three groups. Prism 8.01 software (GraphPad Inc.) was used for the statistical analyses. $P<0.05$ was considered to be statistically significant for all analyses.

\section{Results}

\section{Endometrial epithelium and stroma}

We collected endometrial samples from healthy women undergoing benign gynecological surgery and prepared primary human endometrial epithelial cells and stromal cells from the endometrial samples by enzymatic digestion for in vitro experiments (Table 1, Fig. 1a-d). During culture of stromal cells, epithelial cells were observed at early passages; however, they disappeared after serial passages (Fig. 1c, d). We failed to culture the endometrial cells from the endometrial samples derived from older patients and patients in the secretory phase of their cycles because the cells ceased proliferating. Endometrial cells may have differential growth properties that depend on donor age and menstrual phase.

We then examined the thawed endometrial cells to investigate whether endometrial characteristics were preserved (Fig. 1e-g). Endometrial cells in culture exhibited a single columnar epithelium structure and spindleshaped fibroblast-like morphology that were similar to normal endometrial tissue. For endometrial stromal cells, we further explored protein expression and hormone responsiveness (Fig. 1h-l). Endometrial stromal cells presented the same protein expression pattern as endometrial tissue. We successfully induced decidualization in endometrial cells which exhibited aggregation of large cells with abundant cytoplasm, marked nucleolar enlargement and prominent nuclei (Fig. 1i, j; Supplemental Figure 1). Additionally, the decidualization markers $P R L$ and IGFBP1 were significantly upregulated in the decidualized cells ( $P=0.0017$ and 0.0033 , respectively) (Fig. $1 \mathrm{k}, \mathrm{l})$, suggesting that hormone responsiveness is preserved in endometrial stromal cells even after the freeze-thaw procedure and subsequent passages.

\section{Successful cultivation of endometrial epithelial cells with feeder cells}

We then examined various cells as feeders for endometrial epithelium (Fig. 2a-f). We serially passaged endometrial epithelial cells on mouse embryonic fibroblasts (MEF) up to 6 passages for approximately 4 months (Fig. 2b). Since the adhesive ability of MEFs was low, MEFs were easily separated from the endometrial epithelial cells. The endometrial epithelial cells were efficiently propagated on MEFs, as shown by the cumulative area of colonies $(P<0.05)$, area of colonies $(P<0.05)$, and population doubling $(P=0.016)$ (Fig. 2a-f). Endometrial epithelial cells on MEF showed a cobblestone appearance and expressed pan-cytokeratin, an epithelial cell-specific marker, at passage 4 (Fig. 2g, Supplemental Figure 2A). Interestingly, endometrial epithelial cells on MEF lost expression of vimentin, which is expressed in both endometrial epithelial cells and stromal cells.

\section{Patient-derived endometrial stromal cell is one of the best human feeder cells}

Anticipating clinical applications, we examined human cells as feeder cells for endometrial epithelial cells. We assumed that endometrial stromal cells simultaneously obtained from the same patient would be good feeders for endometrial epithelial cells. We hypothesized that endometrial stromal cells could serve as feeder cells if their proliferation activities were suppressed. We therefore investigated differences in cell proliferation of endometrial stromal cells in two types of media. Endometrial stromal cells in proliferative and non-proliferative states were spindle-shaped or flat polygonal-shaped, respectively (Fig. 3a, b). The proliferation rate of endometrial stromal cells in the conventional medium (DMEM supplemented with $10 \%$ FBS) was significantly higher than that in the epithelium-specific medium $(P<0.05)$ (Fig. 3c). Based on these findings, we decided to utilize the endometrial stromal cells as feeder cells for subsequent experiments. The endometrial epithelial cells were propagated on endometrial stromal cells up to passage 5 for 81 days (Fig. $3 \mathrm{~d}-\mathrm{g}$ ). Estrogen receptor $\alpha$ and progesterone receptor were preserved in the endometrial epithelial cells (Supplemental Figure 3A and B). Endometrial epithelial cells after serial passages exhibited a cobblestone appearance and expressed pan-cytokeratin, but they failed to express vimentin at early passage (passage 2 ) and late passage (passage 4) (Fig. 3h, Supplemental Figure 3C).

We then examined human-derived cells (hESCFCs) as feeder cells for endometrial epithelial cells. We simultaneously compared feeder activities of endometrial stromal cells and hESCFCs by examination of the proliferation rate of endometrial epithelial cells under the same 
a
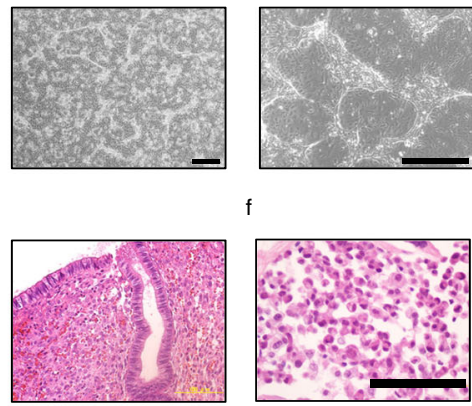

Endometrial tissue
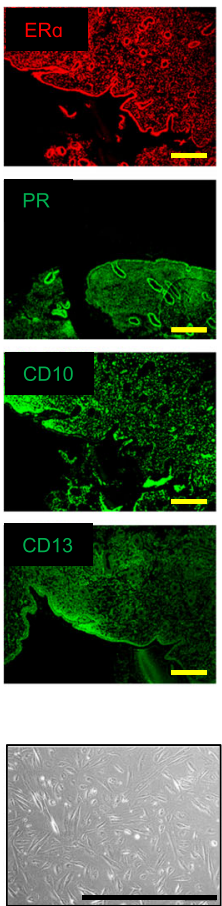
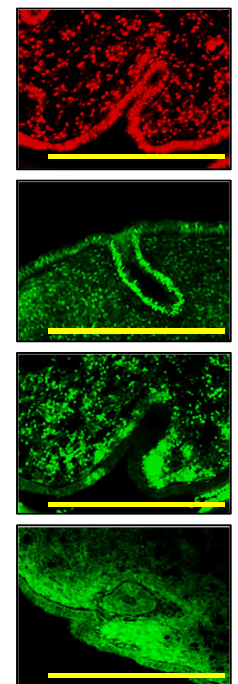

,

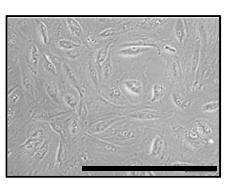

c
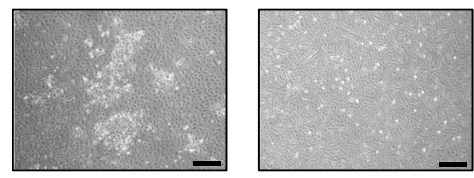

$\mathrm{g}$

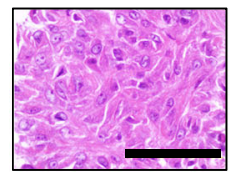

d
Endometrial stromal cells
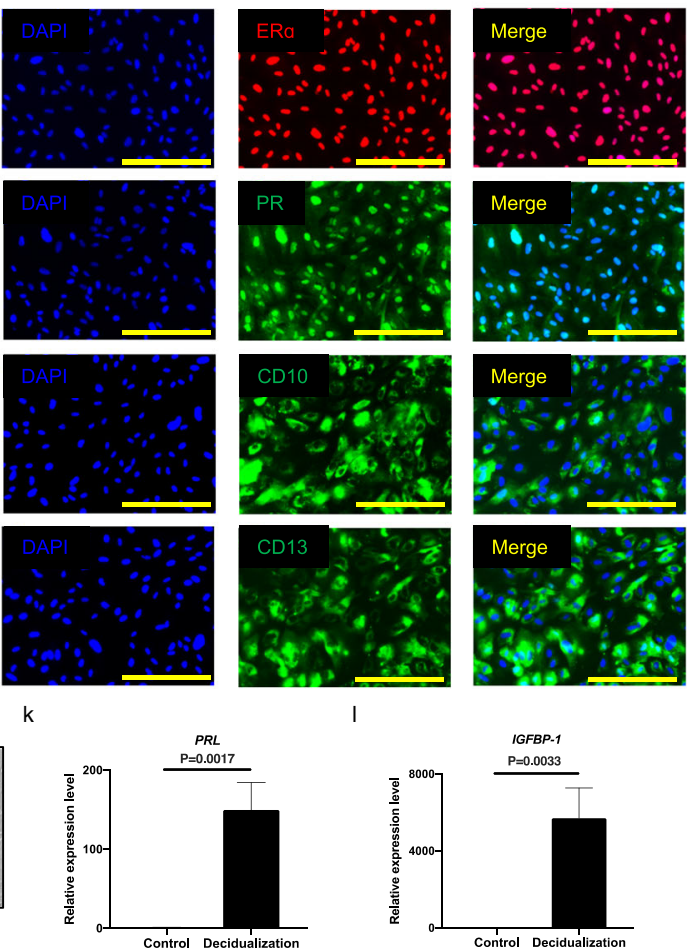

Fig. 1 Preparation of endometrial epithelial cells and stromal cells from endometrial specimens. $\mathbf{a}$, b Microscopic appearance of endometrial epithelial cells in primary culture. Low magnification (a) and high magnification (b). Black bar is $500 \mu \mathrm{m}$. c, d Microscopic appearance of endometrial stromal cells. Epithelial components were mixed in primary culture $(\mathbf{c})$; however, these disappeared with serial passage (d). Black bar is 500 um. e- $\mathbf{g}$ Hematoxylin and eosin staining for endometrial tissue (e), cultured endometrial epithelial cells (f), and stromal cells (g). Black bar is $100 \mu \mathrm{m}$. $\mathbf{h}$ Immunohistochemical staining for endometrial stromal cells in serial culture. Endometrial tissue was used as a control. Endometrial stromal cells were positive for ERa, PR, CD10, and CD13 like endometrial tissue. Nuclei were stained with DAPI. Yellow bar is $500 \mu \mathrm{m}$. Epithelial component of endometrial tissue was positive for ERa and PR, negative for CD10, and weakly positive for CD13. i-I Decidualization of endometrial stromal cells. Microscopic appearance of endometrial stromal cells cultured in the control medium (i) and supplemented with estrogen, progesterone, and cAMP (j) (see Experimental procedure). Black bar is $500 \mu \mathrm{m}$. The $P R L(\mathbf{k})$ and IGFBP-1 (I) genes were significantly upregulated after decidualization $(P=0.0017$ and 0.0033 , respectively). Expression of the genes in the controls is designated as 1.0. Error bar indicates SEM. Each experiment was done in triplicate. Abbreviation: ER, estrogen receptor; PR, progesterone receptor; DAPI, 4',6-diamidino-2-phenylindole; cAMP, cyclic adenosine monophosphate; PRL, prolactin; IGFBP-1, insulin-like growth factor binding protein-1; SEM, standard error of the mean

experimental conditions, including cell density and culture media. The endometrial epithelial cells were successfully cultured on hESCFCs up to passage 5 for 4 months (Fig. 4a-e). Furthermore, we examined the endometrial epithelial cells for morphology and protein expression (Fig. 4f). The endometrial epithelial cells expressed pan-cytokeratin and lost expression of vimentin when cultured with hESCFCs. The proliferation rate of endometrial epithelial cells on the endometrial stromal cells was significantly higher than that on hESCFCs $(P<0.05)$. 
a

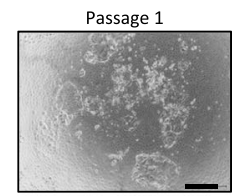

b

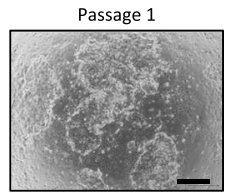

Passage 4

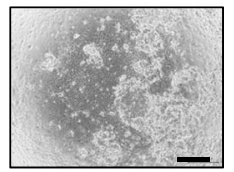

f

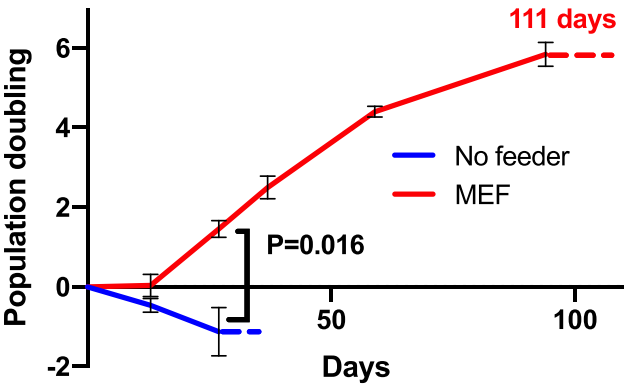

g
Passage 2

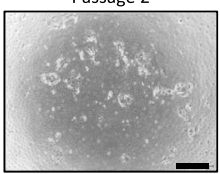

Passage 2

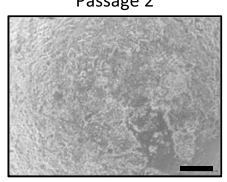

Passage 5

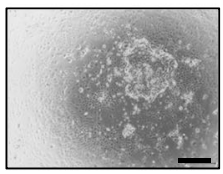

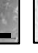

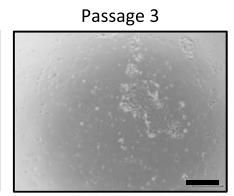

Passage 3

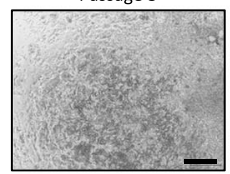

Passage 6

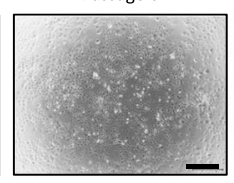

11 days
C

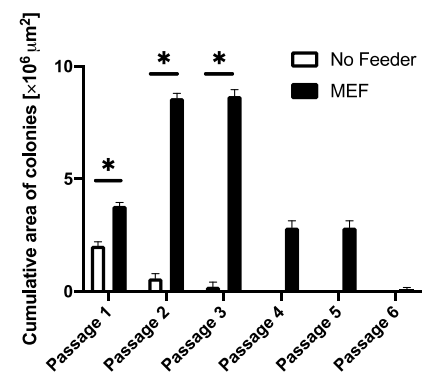

d

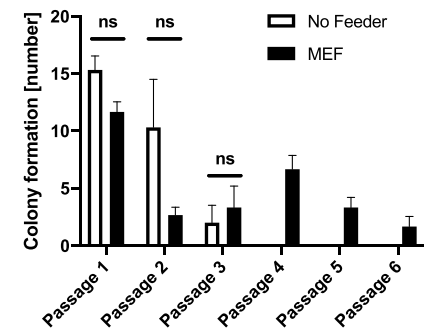

e
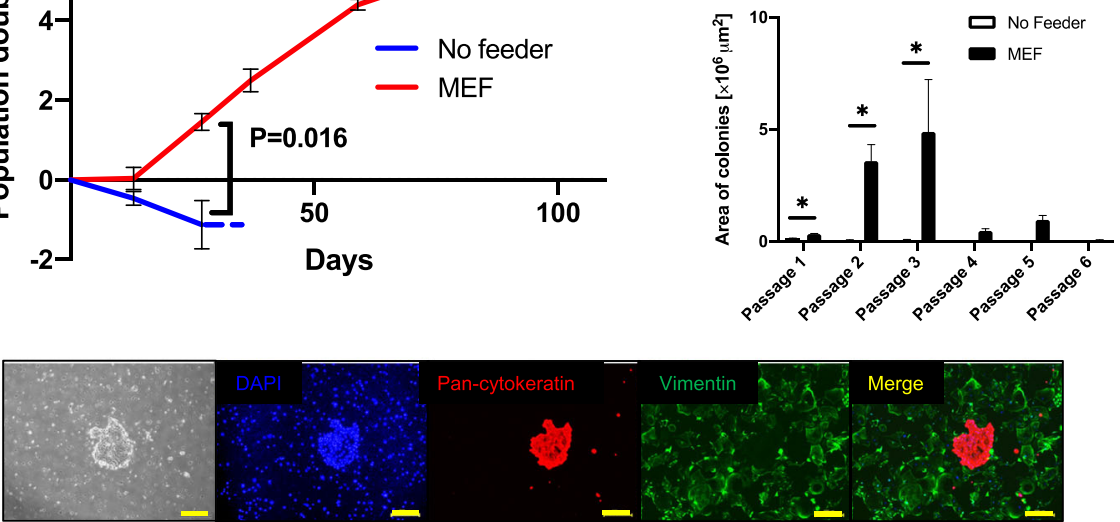

Fig. 2 Culture of endometrial epithelial cells with mouse embryonic fibroblasts. a, b Microscopic appearance of endometrial epithelial cells without feeder cells (a) and with MEF (b) in serial passage. Black bar is 500 m. c- ce Cumulative area of colonies (c), colony formation (number) (d), and area of colonies (e) of endometrial epithelial cells in serial passages. Error bar indicates SEM. An asterisk means $P<0.05$. ns means "not significant". $\mathbf{f}$ Population doubling levels of endometrial epithelial cells when culture with MEF (red) and without feeder cells (blue). We could propagate endometrial epithelial cells with MEF for 111 days. Error bar indicates SEM. Dotted line indicated the observation period until the culture was terminated. $\mathbf{g}$ Immunohistochemical staining for endometrial epithelial cells and MEF at passage 4. Endometrial epithelial cells kept positive for pancytokeratin in serial passage. MEF expressed vimentin. Endometrial epithelial cells did not express vimentin. Nuclei were stained with DAPI. Yellow bar is $500 \mu \mathrm{m}$. Each experiment was done in triplicate. Abbreviation: MEF, mouse embryonic fibroblasts; SEM, standard error of the mean

Endometrial stromal cells can therefore be used as feeder cells to support proliferation of endometrial epithelial cells, as they were among the best human-derived cells tested.

\section{Three-dimensional culture of thawed endometrial cells}

Our successful cultivation of endometrial epithelial cells for use in co-cultures with endometrial stromal cells motivated us to investigate whether three-dimensional culture can be achieved using thawed endometrial cells. We investigated whether variation in the numbers of endometrial stromal cells in the atelocollagen gel affects three-dimensional-culture (Fig. 5a-c). Construction of artificial endometrium network depended on the number of endometrial stromal cells. Endometrial stroma was evenly embedded in the atelocollagen gel. Endometrial stromal cells $\left(1 \times 10^{6}\right.$ cells $)$ embedded in atelocollagen formed stromal layer, and gradually shrunk during 7 days of culture (Fig. 5d). We then plated endometrial epithelial cells on formed stromal layers and maintained the three-dimensional-culture for 14 days (Fig. 5e-g). Epithelial cells in three-dimensional-culture were positive for both epithelial markers (cytokeratins and Ecadherin) and mesenchymal markers (vimentin and CD13), like intact human endometrium (Fig. 5h, 


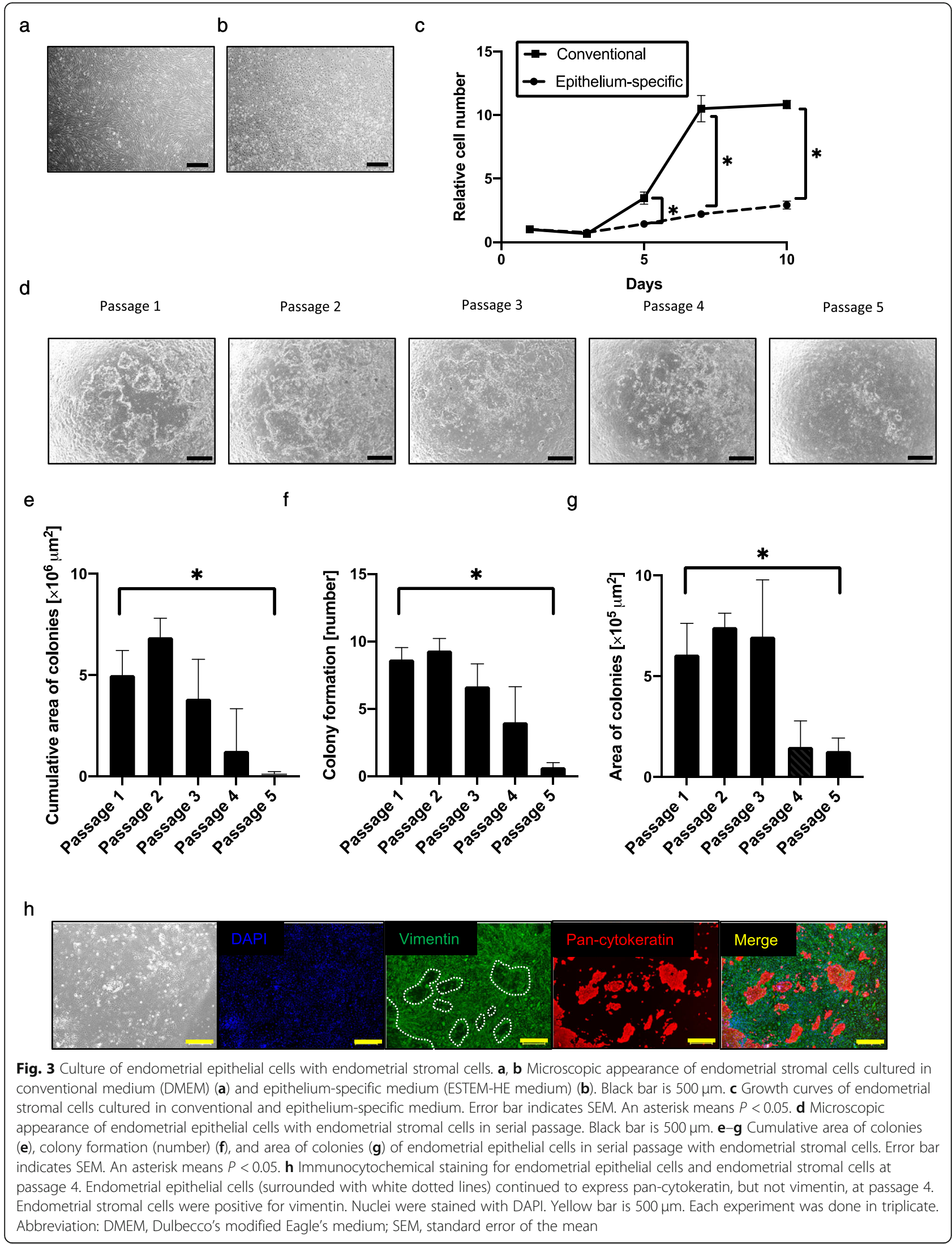




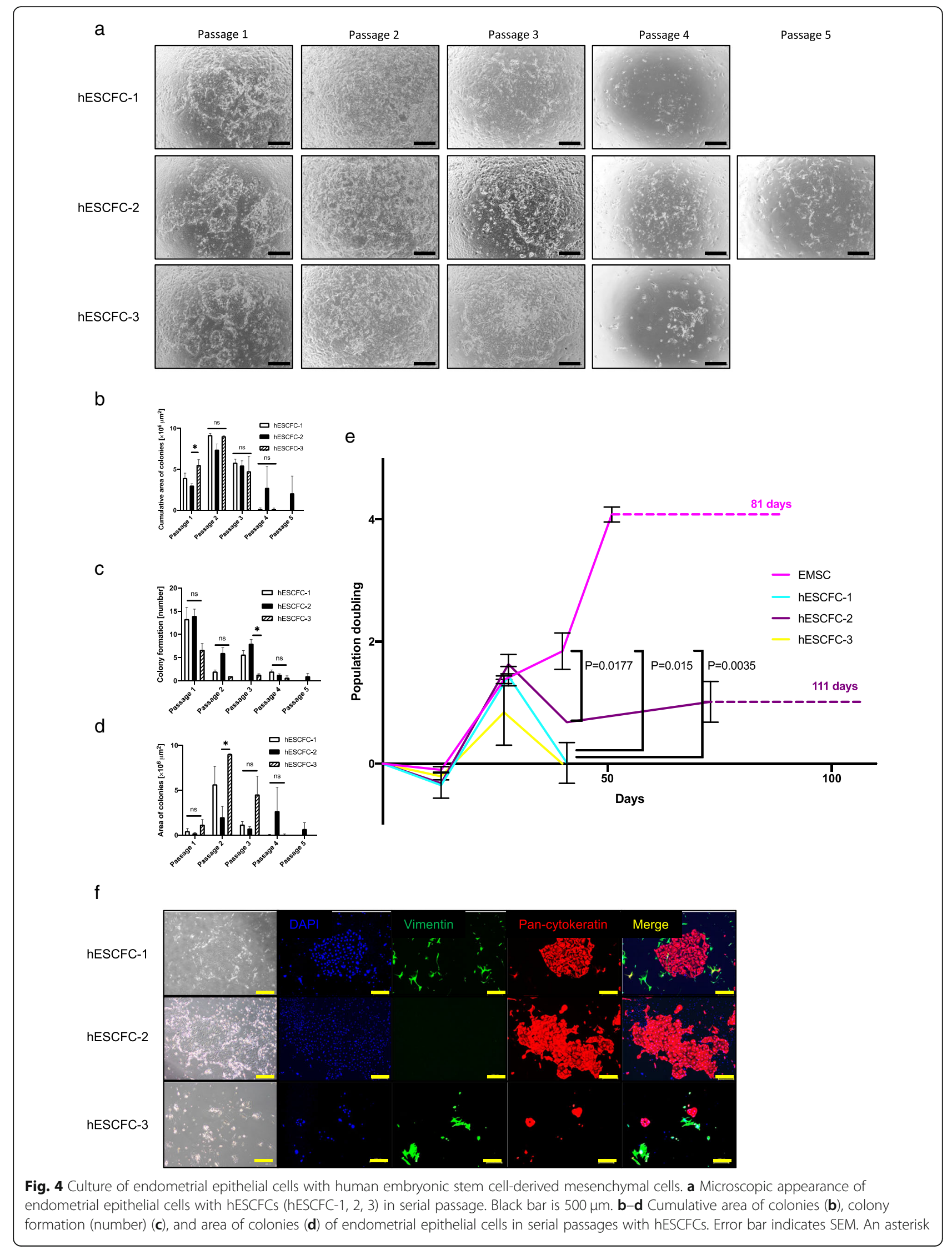




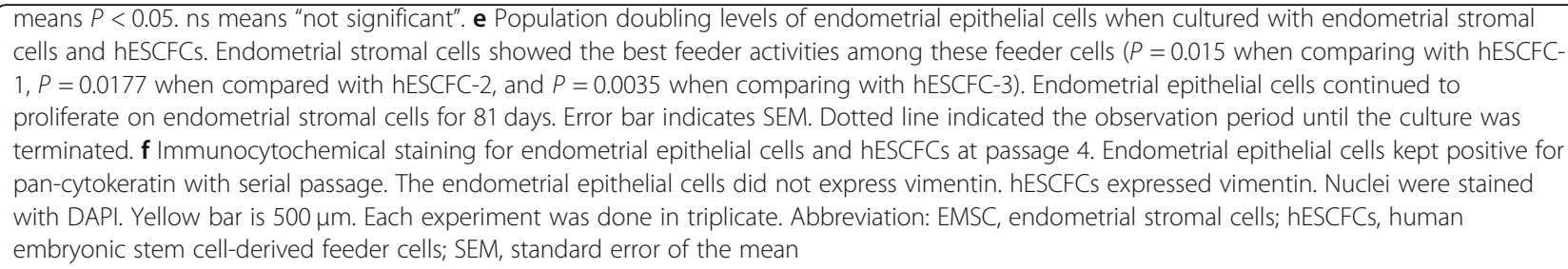

Supplemental Figure 2B). These data suggest that endometrial epithelium and stroma, after the freeze-thaw procedure and sequential culture, are able to establish an endometrial three-dimensional model. The success of this study may lead to the development of an in vitro implantation model.

\section{Discussion}

It is difficult to maintain endometrial epithelial cells in vitro and co-culture them with endometrial stromal cells. Similar three-dimensional-structures have been established in the cornea, intestine, and liver [20-22]. Likewise, we hypothesized that an endometrial threedimensional model can be established. In this study, we demonstrated that endometrial stroma is one of the best feeder cell types for propagation of endometrial epithelium. We also established an endometrial threedimensional model with frozen-thaw endometrial epithelial cells and endometrial stromal cells.

\section{Endometrial stromal cells as feeder cells}

Feeder cells have the capacity to support in vitro survival and growth of orthologous epithelial or parenchymal cells through a variety of soluble or membrane-bound growth factors and receptors [23-25]. Functional epithelial and parenchymal cell types are dependent on physical contact with feeder cells for survival and expansion. On the other hand, feeder-dependent cells can also be grown under feeder-free conditions when coated with extracellular matrix proteins such as laminin, vitronectin, or a mixture of the extracellular matrix components [26-29]. Feeder cells usually consist of adherent growth-arrested, but viable cells. It may be necessary to maintain feeder cells in a nonmultiplying state by irradiation or exposure to anticancer drugs to prevent overgrowth [23]. This is observed in other types of feeder cells such as MEFs and immortalized feeder cells [30-35]. Irradiation of the feeder cells, i.e., MEFs, hESCFC- 1 cells, hESCFC- 2 cells, and hESCFC- 3 cells with an inducible Tet-ON system, indeed enabled us to establish the endometrial model, implying that endometrial epithelial cells are supported by non-dividing endometrial stromal cells, but not endometrial stromal cells retaining proliferation activities. This finding motivated us to use endometrial stromal cells as feeder cells. Indeed, this study showed that endometrial stromalderived cells are able to support long-term survival and growth of endometrial epithelial cells. We also investigated feeder activities of hESCFCs established in our laboratory. hESCFCs were easy to maintain. Furthermore, other types of human cells such as epidermal cells, intestinal epithelial cells, and hepatocytes can be propagated on hESCFCs in our laboratory (not published). These results motivated us to investigate whether hESCFCs can accelerate proliferation of endometrial epithelial cells. As for the differences among the feeder cells, various combinations of the genes have been transduced to investigate which genes contribute to good feeder activities. hESCFCs contribute the small success to propagate the endometrial epithelial cells. However, the difference among hESCFCs was subtle; Wnt3a and Rspo1 are sufficient to confer efficient feeder activity to hESCFCs. Further studies will be needed to clarify which genes are necessary to support proliferation of not only endometrial epithelial cells, but also other types of human epithelial or parenchymal cells.

The underlying mechanisms for the successful expansion of endometrial epithelium on homologous stroma developed in this study were not revealed; however, previous reports suggest that the FGF-MAPK, WNT-R-spondin-3, BMPNoggin, and TGF $\beta$ signaling pathways are involved $[12,13$, 36]. The success of endometrial epithelial cell proliferation via cell interaction is attributed to four mechanisms: First, endometrial stromal cells secrete signal molecules that act as local mediators, affect cells in the immediate environment, and exert a paracrine effect on endometrial epithelial cells [37]. Second, cell membrane-bound molecules of endometrial stromal cells influence endometrial epithelial cells [38]. Third, endometrial stromal cells contribute to the stabilization of the culture environment by producing extracellular matrices [39]. Fourth, the heterocellular contribution of endometrial stromal cells to endometrial epithelial cells may be through gap junctions [40].

\section{Potential clinical application}

The culture method developed in this study has four strengths that suggest the cells will be useful for clinical applications. First, we employed a simplified culture method which acquires more viable cells without usage of magnetic cell sorting and/or fluorescence-activated cell sorting. Second, patient-derived endometrial stromal cells can be substituted for Matrigel. Third, we show proof-ofconcept regarding the use of frozen cells; we successfully 
a

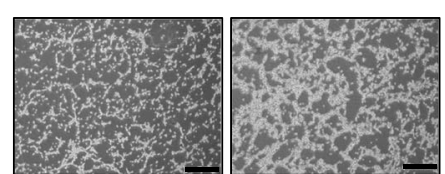

b
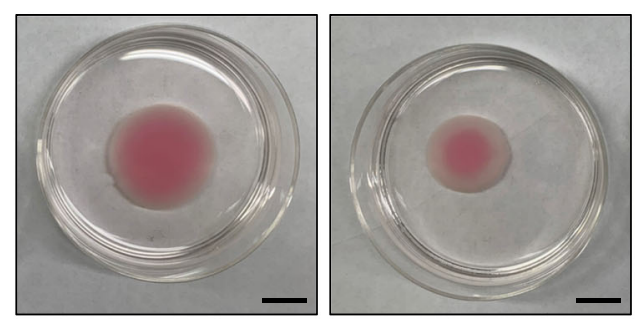

C
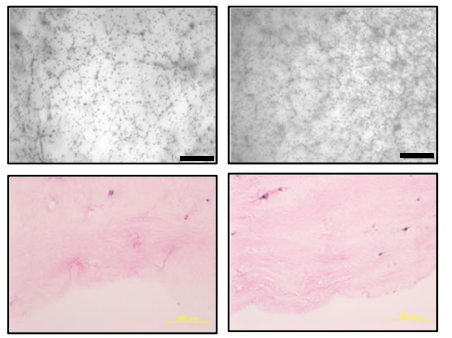

d

Day 0

Day 7

Day 21
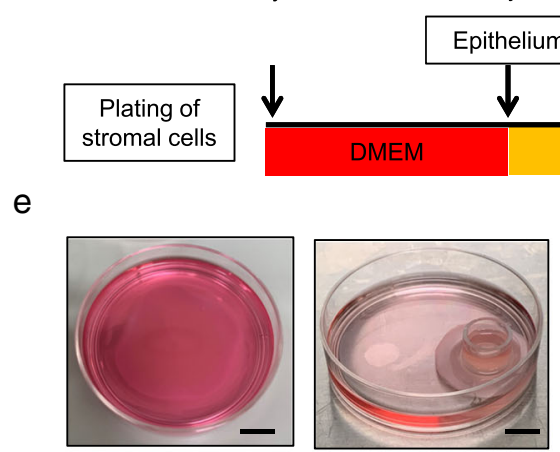

e
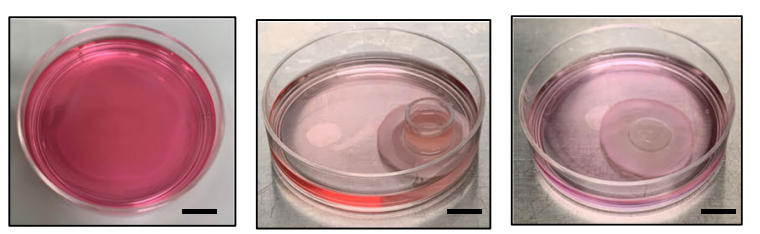

f

h
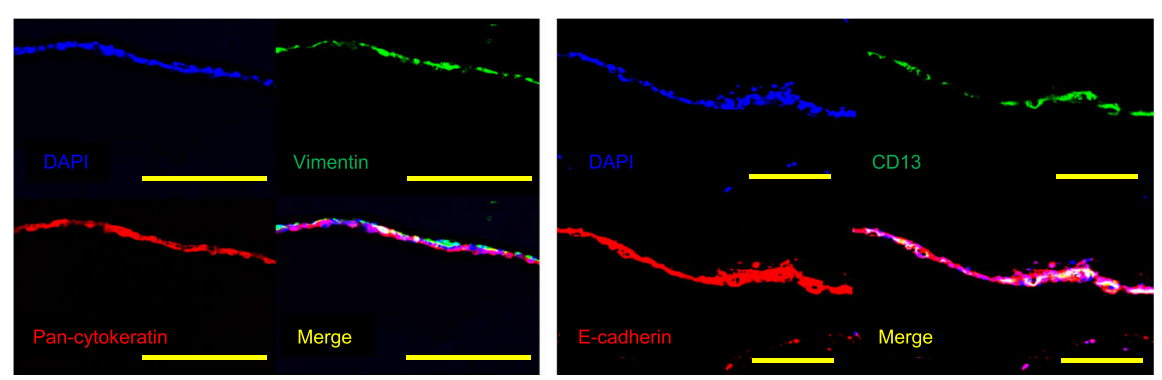

Fig. 5 Endometrial three-dimensional cell culture model. a Microscopic appearance of endometrial stromal cells embedded in atelocollagen on Day 1. Cell numbers were $1 \times 10^{6} \mathrm{cells}$ (left) and $2 \times 10^{6} \mathrm{cells}$ (right), respectively. Black bar is $500 \mu \mathrm{m}$. b Gross appearance of endometrial stromal cells embedded in atelocollagen on day 7. Cell numbers were $1 \times 10^{6} \mathrm{cells}$ (left) and $2 \times 10^{6} \mathrm{cells}$ (right), respectively. Black bar is $1 \mathrm{~cm}$. c Microscopic appearance (bright field and HE staining) of endometrial stromal cells embedded in atelocollagen on day 7 . Cell numbers were $1 \times 10^{6} \mathrm{cells}$ (left) and $2 \times 10^{6}$ cells (right), respectively. Black bar is $1 \mathrm{~cm}$. $\mathbf{d}$ Protocol for three-dimensional cell culture. e Gross appearance of endometrial three-dimensional cell culture. Endometrial stromal cells were embedded in atelocollagen (left), then endometrial epithelial cells were plated on formed stromal layers using a glass ring on day 7 (middle). Endometrial three-dimensional model was developed during further 14 days of culture (right). $\mathbf{f} \mathrm{HE}$ staining for three-dimensional cultured endometrial cells. Black bar is $100 \mu \mathrm{m}$. g Magnification of box area in figure $\mathbf{f}$. Endometrial epithelial cells (arrows) and stromal cells (arrowheads) in three-dimensional cell culture. Black bar is $50 \mu \mathrm{m} . \mathbf{h}$ Immunohistochemistry of endometrial cells in three-dimensional culture. The endometrial epithelial cells were positive for pan-cytokeratin, vimentin, E-cadherin, and CD13. This is consistent with expression of these markers in intact endometrial tissue. Nuclei were stained with DAPI. Yellow bar is $200 \mu \mathrm{m}$

utilized thawed endometrial cells that were cultured for more than 3 months. Indeed, cryopreservation of freshly biopsied tissue was challenged [41]. These findings are critical for clinical application from the viewpoint that reproductive endocrinologists prepare patient-derived endometrial cells for ongoing fertility treatment in a clinical setting. Fourth, endometrial stromal cells served the best condition for endometrial epithelial cells in vitro. 
Epithelial cells in vivo require close interaction with surrounding mesenchymal cells [23]. To solve the problem of thin endometrium with regenerative medicine, we used endometrial somatic cells as a source of epithelial cells and feeder cells. Alternatively, endometrium-derived pluripotent stem cells and progenitors may also be an attractive source [42]. Although refinement of the protocol and proof-of-concept by in vivo experimentation are needed before applying these cells in clinical practice, findings from our study can lead to development of novel therapeutic strategies in fertility medicine.

\section{Conclusions}

Our study demonstrates not only the promise for in vitro endometrial regeneration, but also advances our understanding of reproductive biology. Novel in vitro approaches, including modifying embryo culture socalled "in vitro implantation", may be possible therapeutic approaches to increase success rates of fertility treatment and diminish unnecessary miscarriage.

\section{Supplementary Information}

The online version contains supplementary material available at https://doi. org/10.1186/s13287-021-02188-x.

Additional file 1: Supplemental Figure 1. Protocol of decidualization. Control medium was DMEM with low-serum medium (2\% FBS) and Penstrep. For decidualization, $\beta$-estradiol, progesterone and 8-Br-cAMP were added in control medium as supplement. Medium replacement (MR) was performed every other day.

Additional file 2: Supplemental Figure 2. Immunohistochemistry for endometrial tissues. (A) The epithelial component of endometrial tissue is positive for pan-cytokeratin and vimentin. Nuclei were stained with DAPI. Yellow bar is $200 \mu \mathrm{m}$. (B) The epithelial component of endometrial tissue is positive for E-cadherin and vimentin. Nuclei were stained with DAPI.

Yellow bar is $200 \mu \mathrm{m}$.

Additional file 3: Supplemental Figure 3. Immunocytochemical staining for endometrial epithelial cells cultured on endometrial stromal cells at passage 2. A, B: Endometrial epithelial cells (surrounded with white dotted lines) remained positive for estrogen receptor a (A: ERa) and progesterone receptor (B: PR). C: Endometrial epithelial cells (surrounded with white dotted lines) were positive for pan-cytokeratin. Endometrial stromal cells expressed vimentin, but endometrial epithelial cells did not. Yellow bar is $100 \mu \mathrm{m}$.

Additional file 4: Supplemental Table 1. List of vectors and genes.

\section{Acknowledgements}

We would like to express our sincere thanks to K. Miyado and H. Akutsu for fruitful discussion, to M. Ichinose for providing expert technical assistance, to C. Ketcham for English editing and proofreading, and to E. Suzuki and K. Saito for secretarial work.

\section{Authors' contributions}

Conceptualization: RY, AU. Data curation: RY, YF, HK. Formal analysis: RY, YF, AU. Funding acquisition: RY, AU. Investigation: RY, YF, HK, SN. Methodology: RY, TK, AU. Project administration: AO, HS, AU. Software: RY, YF. Supervision: $H K, A O, H S, A U$. Writing-original draft: RY. Writing-review and editing: $A O$, $H S, A U$. The authors read and approved the final manuscript.

\section{Funding}

This research was supported by The Jikei University Research Fund for Graduate Students; by JSPS KAKENHI Grant Number JP20J14152; by the Grant of National Center for Child Health and Development.

\section{Availability of data and materials}

The datasets used and/or analyzed during the current study are available from the corresponding author on reasonable request

\section{Ethics approval and consent to participate}

The protocol for the use of human cells in the present study was approved by the Institutional Review Board of the National Center for Child Health and Development of Japan (approval number: 2289) and The Jikei University School of Medicine (approval number: 28-083(8326)) and was in full compliance with the Ethical Guidelines for Clinical Studies (Ministry of Health, Labor, and Welfare). The animal use protocol was approved by the Institutional Animal Care and Use Committee of the National Center for Child Health and Development. All animal experiments were based on the $3 \mathrm{R}$ principle (refine, reduce, and replace), and all efforts were made to minimize animal suffering and to reduce the number of animals used.

\section{Consent for publication}

Not applicable.

\section{Competing interests}

The authors declare that there is no conflict of interest regarding the work described herein.

\section{Author details}

${ }^{1}$ Center for Regenerative Medicine, National Center for Child Health and Development Research Institute, 2-10-1 Okura, Setagaya, Tokyo 157-8535, Japan. ${ }^{2}$ Center for Maternal-Fetal, Neonatal and Reproductive Medicine, National Center for Child Health and Development, 2-10-1 Okura, Setagaya, Tokyo 157-8535, Japan. ${ }^{3}$ Department of Obstetrics and Gynecology, The Jikei University School of Medicine, 3-25-8 Nishi-Shinbashi, Minato, Tokyo 105-8461, Japan. ${ }^{4}$ Project for Prevention of HPV-related Cancer, Exploratory Oncology Research and Clinical Trial Center, National Cancer Center, Chiba 277-8577, Japan

Received: 5 December 2020 Accepted: 24 January 2021

Published online: 12 February 2021

\section{References}

1. Vander Borght M, Wyns C. Fertility and infertility: definition and epidemiology. Clin Biochem. 2018;62:2-10.

2. Abrao MS, Muzii L, Marana R. Anatomical causes of female infertility and their management. Int J Gynaecol Obstet. 2013;123(Suppl 2):S18-24.

3. Zhang T, Li Z, Ren X, Huang B, Zhu G, Yang W, et al. Endometrial thickness as a predictor of the reproductive outcomes in fresh and frozen embryo transfer cycles: a retrospective cohort study of 1512 IVF cycles with morphologically good-quality blastocyst. Medicine. 2018;97 Wolters Kluwer Health. Available from: https://www.ncbi.nlm.nih.gov/pmc/articles/pmc5 794374/.

4. Griebel CP, Halvorsen J, Golemon TB, Day AA. Management of spontaneous abortion. Am Fam Physician. 2005;72:1243-50.

5. Keung JJ, Spies JB, Caridi TM. Uterine artery embolization: a review of current concepts. Best Pract Res Clin Obstet Gynaecol. 2018;46:66-73.

6. Sentilhes L, Gromez A, Clavier E, Resch B, Verspyck E, Marpeau L. Fertility and pregnancy following pelvic arterial embolisation for postpartum haemorrhage. BJOG. 2010;117:84-93.

7. Mahajan N, Sharma S. The endometrium in assisted reproductive technology: how thin is thin? J Hum Reprod Sci. 2016;9:3-8.

8. Gao G, Cui X, Li S, Ding P, Zhang S, Zhang Y. Endometrial thickness and IVF cycle outcomes: a meta-analysis. Reprod BioMed Online. 2020;40:124-33.

9. Lebovitz O, Orvieto R. Treating patients with "thin" endometrium - an ongoing challenge. Gynecol Endocrinol. 2014;30:409-14.

10. Maleki-Hajiagha A, Razavi M, Rouholamin S, Rezaeinejad M, Maroufizadeh S, Sepidarkish M. Intrauterine infusion of autologous platelet-rich plasma in women undergoing assisted reproduction: a systematic review and metaanalysis. J Reprod Immunol. 2020;137:103078. 
11. Tan J, Li P, Wang Q, Li Y, Li X, Zhao D, et al. Autologous menstrual bloodderived stromal cells transplantation for severe Asherman's syndrome. Hum Reprod. 2016;31:2723-9.

12. Chen JC, Erikson DW, Piltonen TT, Meyer MR, Barragan F, Mclntire RH, et al. Coculturing human endometrial epithelial cells and stromal fibroblasts alters cellspecific gene expression and cytokine production. Fertil Steril. 2013;100:1132-43.

13. Turco MY, Gardner L, Hughes J, Cindrova-Davies T, Gomez MJ, Farrell L, et al. Long-term, hormone-responsive organoid cultures of human endometrium in a chemically defined medium. Nat Cell Biol. 2017;19:568-77.

14. Katoh N, Kuroda K, Tomikawa J, Ogata-Kawata H, Ozaki R, Ochiai A, et al. Reciprocal changes of $\mathrm{H} 3 \mathrm{~K} 27 \mathrm{ac}$ and $\mathrm{H} 3 \mathrm{~K} 27 \mathrm{me} 3$ at the promoter regions of the critical genes for endometrial decidualization. Epigenomics. 2018;10:1243-57.

15. Akutsu H, Machida M, Kanzaki S, Sugawara T, Ohkura T, Nakamura N, et al. Xenogeneic-free defined conditions for derivation and expansion of human embryonic stem cells with mesenchymal stem cells. Regen Ther. 2015;1:18-29.

16. Ando Y, Saito M, Machida M, Yoshida-Noro C, Akutsu H, Takahashi M, et al. Can human embryonic stem cell-derived stromal cells serve a starting material for myoblasts? Stem Cells Int. 2017;2017:7541734.

17. Nishiwaki M, Toyoda M, Oishi Y, Ishida S, Horiuchi S-I, Makino-Itou H, et al. Immortalization of human hepatocytes from biliary atresia with CDK4R24C, cyclin D1, and TERT for cytochrome P450 induction testing. Sci Rep. 2020; 10:17503.

18. Schindelin J, Arganda-Carreras I, Frise E, Kaynig V, Longair M, Pietzsch T, et al. Fiji: an open-source platform for biological-image analysis. Nat Methods. 2012;9:676-82.

19. Kajiwara K, Tanemoto T, Wada S, Karibe J, Ihara N, Ikemoto Y, et al. Fetal therapy model of myelomeningocele with three-dimensional skin using amniotic fluid cell-derived induced pluripotent stem cells. Stem Cell Reports. 2017:8:1701-13.

20. Hayashi $R$, Ishikawa $Y$, Sasamoto $Y$, Katori $R$, Nomura N, Ichikawa $T$, et al. Coordinated ocular development from human iPS cells and recovery of corneal function. Nature. 2016:531:376-80.

21. Uchida H, Machida M, Miura T, Kawasaki T, Okazaki T, Sasaki K, et al. A xenogeneic-free system generating functional human gut organoids from pluripotent stem cells. JCl Insight. 2017;2:e86492.

22. Koike H, Iwasawa K, Ouchi R, Maezawa M, Giesbrecht K, Saiki N, et al. Modelling human hepato-biliary-pancreatic organogenesis from the foregut-midgut boundary. Nature. 2019:574:112-6.

23. Llames S, García-Pérez E, Meana Á, Larcher F, del Río M. Feeder layer cell actions and applications. Tissue Eng Part B Rev. 2015;21:345-53.

24. Green H. Terminal differentiation of cultured human epidermal cells. Cell. 1977;11:405-16.

25. Hynds RE, Bonfanti P, Janes SM. Regenerating human epithelia with cultured stem cells: feeder cells, organoids and beyond. EMBO Mol Med. 2018;10:139-50.

26. Miyazaki T, Futaki S, Suemori $H$, Taniguchi $Y$, Yamada M, Kawasaki M, et al. Laminin E8 fragments support efficient adhesion and expansion of dissociated human pluripotent stem cells. Nat Commun. 2012;3:1236.

27. Rodin S, Domogatskaya A, Ström S, Hansson EM, Chien KR, Inzunza J, et al. Long-term self-renewal of human pluripotent stem cells on human recombinant laminin-511. Nat Biotechnol. 2010;28:611-5.

28. Takayama K, Nagamoto Y, Mimura N, Tashiro K, Sakurai F, Tachibana M, et al. Long-term self-renewal of human ES/iPS-derived hepatoblast-like cells on human laminin 111-coated dishes. Stem Cell Reports. 2013;1:322-35.

29. Nishishita N, Muramatsu M, Kawamata S. An effective freezing/thawing method for human pluripotent stem cells cultured in chemically-defined and feeder-free conditions. Am J Stem Cells. 2015;4:38-49.

30. Ramirez RD, Morales CP, Herbert BS, Rohde JM, Passons C, Shay JW, et al. Putative telomere-independent mechanisms of replicative aging reflect inadequate growth conditions. Genes Dev. 2001;15:398-403.

31. Nakano T, Kodama H, Honjo T. In vitro development of primitive and definitive erythrocytes from different precursors. Science. 1996;272:722-4.

32. Takayama N, Nishikii H, Usui J, Tsukui H, Sawaguchi A, Hiroyama T, et al. Generation of functional platelets from human embryonic stem cells in vitro via ES-sacs, VEGF-promoted structures that concentrate hematopoietic progenitors. Blood. 2008;111:5298-306.

33. Vazin T, Becker KG, Chen J, Spivak CE, Lupica CR, Zhang Y, et al. A novel combination of factors, termed SPIE, which promotes dopaminergic neuron differentiation from human embryonic stem cells. PLoS One. 2009;4:e6606.

34. Nishimura T, Kaneko S, Kawana-Tachikawa A, Tajima Y, Goto H, Zhu D, et al. Generation of rejuvenated antigen-specific $T$ cells by reprogramming to pluripotency and redifferentiation. Cell Stem Cell. 2013;12:114-26.
35. Paerhati $P$, Ito A, Yoshioka K, Iwamoto K, Fujiwara S, Horie M, et al. Neural differentiation of mouse induced pluripotent stem cells using cadherin gene-engineered PA6 feeder cells. J Biosci Bioeng. 2019;127:633-40.

36. Gargett CE, Schwab KE, Zillwood RM, Nguyen HPT, Wu D. Isolation and culture of epithelial progenitors and mesenchymal stem cells from human endometrium. Biol Reprod. 2009:80:1136-45.

37. Roy A, Krzykwa E, Lemieux R, Néron S. Increased Efficiency of $\gamma$-Irradiated versus Mitomycin C-Treated Feeder Cells for the Expansion of Normal Human Cells in Long-Term Cultures. J Hematother Stem Cell Res. 2001;10: 873-80 Mary Ann Liebert, Inc., publishers.

38. Puck TT, Marcus PI. A rapid method for viable cell titration and clone production with HELA cells in tissue culture: the use of $x$-irradiated cells to supply conditioning factors. Proc Natl Acad Sci U S A. 1955:41:432-7.

39. Namba M, Fukushima F, Kimoto T. Effects of feeder layers made of human, mouse, hamster, and rat cells on the cloning efficiency of transformed human cells. In Vitro. 1982;18:469-75.

40. Ehmann UK, Calderwood SK, Stevenson MA. Gap-junctional communication between feeder cells and recipient normal epithelial cells correlates with growth stimulation. In Vitro Cell Dev Biol Anim. 2001;37:100-10.

41. Bui BN, Boretto M, Kobayashi H, van Hoesel M, Steba GS, van Hoogenhuijze $\mathrm{N}$, et al. Organoids can be established reliably from cryopreserved biopsy catheter-derived endometrial tissue of infertile women. Reprod BioMed Online. 2020;41:465-73.

42. Singh P, Bhartiya D. Pluripotent stem (VSELs) and progenitor (EnSCs) cells exist in adult mouse uterus and show cyclic changes across estrus cycle. Reprod Sci. 2021;28:278-90.

\section{Publisher's Note}

Springer Nature remains neutral with regard to jurisdictional claims in published maps and institutional affiliations.

Ready to submit your research? Choose BMC and benefit from:

- fast, convenient online submission

- thorough peer review by experienced researchers in your field

- rapid publication on acceptance

- support for research data, including large and complex data types

- gold Open Access which fosters wider collaboration and increased citations

- maximum visibility for your research: over $100 \mathrm{M}$ website views per year

At $\mathrm{BMC}$, research is always in progress.

Learn more biomedcentral.com/submission 